\title{
SOMATOFORM DISSOCIATION AND SYMPTOMS OF TRAUMATIC STRESS IN ADOLESCENTS
}

\author{
Lubomir Kukla*, Petra Selesova, Petr Okrajek, Jan Tulak \\ Research Institute of Preventive and Social Paediatrics, Medical Faculty, \\ Masaryk University, Brno, Czech Republic \\ Received January 10, 2010; accepted February 4, 2010
}

\begin{abstract}
Dissociation is traditionally attributed to trauma and other psychological stressors although there is evidence that in many cases dissociative symptoms could be attributable to initial brain insult, injury or other organic brain disease. With respect to these findings there is a question to which extent symptoms of somatoform dissociation are related to symptoms of traumatic stress or whether these symptoms may be predominantly attributed to various somatic factors. With this aim we have assessed the relationship between somatoform dissociation and symptoms of traumatic stress in a group of 75 healthy adolescents. Main result of this study indicates statistically significant relationship between somatoform dissociative symptoms and psychosocial stressors measured by symptoms of traumatic stress. Results of this study also show that the symptoms of somatoform dissociation may occur continuously in population and that only in high level of their experience they cause psychopathological states. In this context, result of this study suggests that also mild levels of stress influence somatic feelings that may lead to symptoms that may occur also as a consequence of various somatic factors.
\end{abstract}

Key words: Adolescents; Dissociation; Somatoform dissociation; Stress

\section{INTRODUCTION}

Dissociation is traditionally attributed to trauma and other psychological stressors that are linked to dissociated traumatic memories (Bob, 2003, 2007; Kihlstrom, 2005; Spiegel, 1997). Nevertheless there is evidence that in many cases dissociative symptoms could be attributable to initial brain insult, injury or other organic brain disease (Kihlstrom, 2005; Spiegel, 1997).

This is in agreement with historical and recent findings suggesting that also somatic components of dissociation leading to a lack of integration of somatoform components of experience, reactions, and functions may have a profound role (Nijenhuis, 2000; Nijenhuis et al., 1996; Bob 2008). Historically are these pathological manifestations associated with systematic descriptions performed in 1859 by Pierre Briquet and later comprehensively studied by Pierre Janet, who studied mental and somatic factors as closely connected and understood them as different aspects of a unity (Ellenberger, 1970; Janet, 1890; Nijenhuis, 2000; Bob, 2008). Typical manifestations of somatoform dissociation (Nijenhuis et al., 1996) are motor inhibition or loss of motor control, gastrointestinal symptoms, dissociative seizures, painful symptoms, alterations in perception or alterations in sensation of pain (analgesia, kinesthetic anesthesia)
(Brown \& Trimble, 2000; Kuyk et al., 1999, Bob, 2008) such as unability to register pain or painful affect during traumatic event (Butler et al., 1996; Saxe et al., 2002).

With respect to these findings there is a question to which extent symptoms of somatoform dissociation are related to symptoms of traumatic stress or whether these symptoms may be predominantly atributed to various somatic factors. With this aim we have assessed the relationship between somatoform dissociation and symptoms of traumatic stress in a group of healthy adolescents.

\section{MATERIALS AND METHODS}

\section{Participants}

Within the framework of ELSPAC (European Longitudinal Study of Parenthood and Childhood) study we have assessed symptoms of somatoform dissociation and symptoms of traumatic stress in 75 healthy 18 years adolescents predominantly with high-school education. All the participants gave written informed consent and the study was approved by university ethical committee.

\section{Psychometric measures}

Somatoform dissociative symptoms were assessed using the 20-item self-reported somatoform dissociation questionnaire SDQ-20 (Nijenhuis et al., 1996). Somatoform 
dissociative symptoms represent alterations in sensations of pain (analgesia, kinesthetic anesthesia), alterations of perception, loss of motor control, gastrointestinal symptoms, etc. Subjects indicate the degree of their experience on 5-point Likert scale. We have used the Czech version of the SDQ-20 that displays high reliability and internal consistency (Cronbach's alpha 0.91 , test-retest reliability after week 0.90 ).

For investigation of childhood traumas, TSC-40 (Trauma Symptom Checklist) (Briere, 1996) was used. TSC40 is a self-reported 40 -item questionnaire done on a 4point Likert scale. TSC-40 evaluates symptomatology in adults associated with childhood or adult traumatic experiences and measures aspects of posttraumatic stress and other symptom clusters found in some traumatized individuals. The Czech version of the TSC-40 has high reliability and internal consistency (Cronbach's alpha 0.91 , test-retest reliability after week 0.88 ).

\section{Statistical methods}

Statistical evaluation of the psychometric measures included common methods of descriptive and inferential statistics. For quantitative assessment means, standard deviations and Pearson product-moment correlation for independent samples were used. In the statistical evaluation the software package Statistica version 6 was used.

\section{Results}

Results of the present study indicate statistically significant relationship between somatoform dissociative symptoms and psychosocial stressors measured by symptoms of traumatic stress. Main result represents highly significant correlation between psychic dissociative symptoms measured by SDQ-20 and TSC-40 ( $\mathrm{r}=0.43, \mathrm{p}=0.000118$ ) (Fig. 1).

Results of descriptive statistic indicate (Table 1) that the group of participants included in this study did not contain individuals with high level of traumatization that is defined by TSC-40 score higher or equal to 70 (Briere, 1996).

Table 1. Results of descriptive statitics for somatoform dissociation (SDQ-20) and symptoms of traumatic stress (TSC-40).

\begin{tabular}{llllll}
\hline & Mean & Median & Minimum & Maximum & S.D. \\
& & & & & \\
\hline SDQ-20 & 22.57 & 21.00 & 20.00 & 32.00 & 2.90 \\
TSC-40 & 14.16 & 13.00 & 0.00 & 39.00 & 9.09 \\
\hline
\end{tabular}

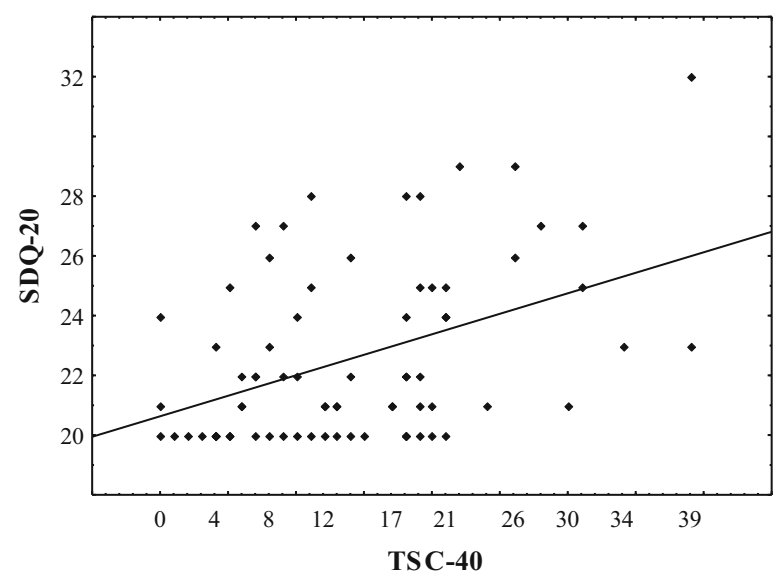

Figure1. Dependency graph between somatoform dissociation (SDQ-20) and symptoms of traumatic stress (TSC-40), $(\mathrm{r}=0.43, \mathrm{p}=0.000118)$.

\section{DISCUSSION}

The results suggest that to some extent symptoms of somatoform dissociation are related to symptoms of traumatic stress although various somatic factors also may play a role in the occurrence of these somatic experiences. Although this result presents preliminary finding the study indicates that in the group of healthy adolescents we have found occurrence of somatoform dissociative symptoms in agreement with the concept of dissociative continuum.

With respect to this concept, results of this study indicate that the symptoms may occur continuously in population and that only in high level of their experience they cause pathological states. In this context, result of this study suggests that also mild levels of stress influence somatic feelings that may lead to symptoms that may occur also as a consequence of various somatic factors.

Although this study does not present "hard data" findings presented in this preliminary report may present important and potentially interesting data for preventive pediatrics that may help to understand the role of stress and dissociation in pathogenesis of several somatic symptoms, and their potential relationship to various somatic diseases in children and adolescents.

\section{Acknowledgement}

This work was supported by grant of Internal Grant Agency of Ministry of Health No. NS 9669-4/2008.

\section{REFERENCES}

Bob, P. (2003). Subliminal processes dissociation and the 'I'. Journal of Analytical Psychology, 48, 307-316. 
Bob, P. (2007). Chaotic patterns of electrodermal activity during dissociated state released by hypnotic abreaction. International Journal of Clinical and Experimental Hypnosis, 55, 435-436.

Bob, P. (2008). Pain, dissociation and subliminal selfrepresentations. Consciousness and Cognition, 17, 355369.

Briere, J. (1996). Psychometric review of the Trauma Symptom Checklist-40, In B.H. Stamm, (Ed.), Measurement of stress, trauma, and adaptation. Lutherville: Sidran Press.

Brown, R.J. and Trimble, M.R. (2000). Dissociative psychopathology, non-epileptic seizures, and neurology. Journal of Neurology, Neurosurgery and Psychiatry, 69, 285-9.

Butler, L.D., Duran, R.E.F., Jasiukaitis, P., Koopman, CH. and Spiegel, D. (1996). Hypnotizability and Traumatic Experience: A Diathesis-Stress Model of Dissociative Symptomatology. American Journal of Psychiatry, Festschrift Supplement, 153, 42-62.

Ellenberger, H.F. (1970). The Discovery of the Unconscious: The History and Evolution of Dynamic Psychiatry. New York: Basic.

Janet, P. (1890). L'Automatisme Psychologique. Paris: Felix Alcan.

Kihlstrom, J.F. (2005). Dissociative disorders. Annual Review of Clinical Psychology 1, 227-253.

Kuyk, J., Spinhoven, P., Van Emde Boas, W., and Van Dyck, R. (1999). Dissociation in Temporal Lobe Epilepsy and Pseudo-Epileptic Seizure Patients. Journal of Nervous and Mental Disease, 187, 713-720.

Nijenhuis, E.R.S. (2000). Somatoform dissociation: major symptoms of dissociative disorders. Journal of Trauma and Dissociation, 1, 7-32.

Nijenhuis, E.R.S., Spinhoven, Ph., Van Dyck, R., Van Der Hart O. and Vanderlinden, J. (1996). The development and psychometric characteristics of the somatoform dissociation questionnaire (SDQ- 20). Journal of Nervous and Mental Disease, 184, 688-694.

Saxe, G. N., Chawla, N., and van der Kolk, B. (2002). Self-destructive behavior in patiens with dissociative disorders. Suicide and Life-Threatening Behavior, 32, 313-319.

Spiegel, D. (1991). Neurophysiological correlates of hypnosis and dissociation. Journal of Neuropsychiatry and Clinical Neurosciences, 3, 440-5. 